\title{
Kinetochore Scaffold 1
}

National Cancer Institute

\section{Source}

National Cancer Institute. Kinetochore Scaffold 1. NCI Thesaurus. Code C97380.

Kinetochore scaffold 1 (2342 aa, $265 \mathrm{kDa}$ ) is encoded by the human KNL1 gene. This protein is involved in the attachment of kinetochores to spindle microtubules. 